\title{
Pengaruh Pendidikan Buklet Kesehatan terhadap Perilaku Ibu Hamil terkait Upaya Pencegahan Berat Bayi Lahir Rendah (BBLR) di Kota Semarang (Studi Kasus di Puskesmas Tlogosari Wetan dan Puskesmas Genuk)
}

\author{
Luluk Faizatul Azizah*, Sri Achadi Nugrahaeni**, Cahyono Hadi** \\ *Puskesmas Pandanaran Kota Semarang \\ **Fakultas Kesehatan Masyarakat, Universitas Diponegoro, Semarang \\ Email: luluk.faizatul.azizah@gmail.com
}

\section{ABSTRACT}

Infant mortality rate of low birth weight $(L B W)$ in Semarang city is still high caused by low birth weight. From 509 BBLR infants with $36.6 \%$ of deaths in 2017. This study aims to determine the effect of health booklet education on pregnant women's behavior related to prevention of BBLR in Semarang City.

Caring behavior could influence the service quality that affects patients satisfactory because their physical, emotional, and spiritual needs are fulfilled. The result of patients satisfactory and Bed Occupation Rate (BOR) in Tugurejo Public Hospital shows a decreasing number. The purpose of this research is to analyze the effect of organizational culture, head of ward leadership, and motivation toward caring behavior of the nurses in the medical wards of Tugurejo Public Hospital

Quasi experimental research with pre post test with control group design. The population in this study were all pregnant women in Semarang City from August to September 2017. The study subjects were 82 pregnant women selected by simple purposive sampling. Data were collected by interview using structured questionnaires. Data were analyzed with Mann Whitney.

The results showed an increase the mean score of knowledge in the intervention group from $8,4 \pm 2,1$ (5-14) to $13,4 \pm 1,1$ (11-15) with score $p=0,001$, whereas in the control group from 7,3 $\pm 2,0$ (3-11) to $11,1 \pm 1,3$ (9-13) with score $p=0,001$. The mean score of attitudes score increased from $37,5 \pm 2,3(28-41)$ to 51,9 $\pm 3,2$ (43-60) score $p=0,001$, while the control group from $36,1 \pm 2,2$ (28-41) to $37,2 \pm 2,7$ (2843) score $p=0,001$. The mean score of behavior score increased from 13,4 $\pm 1,9$ (8-18) to $18,1 \pm$ 1,3 (13-20) score $p=0,001$ while the control group from $14 \pm 2,7$ (7-18) to 17,3 $\pm 1,7$ (12-19) score $p=0,018$. Increased knowledge scores ( $p$ $<0.05)$, improved attitudes $(p<0.05$ and behaviors $(p<0.05)$ in the intervention group were higher than those in the control group.

Educational health booklets conducted in Semarang City improve the behavior of pregnant women related to prevention of BBLR. It is hoped that the health booklet will be the addition of educational facilities to the pregnant women.

Keyword: Health Education, Knowledge, Attitude, Behavior of Pregnant Woman, LBW

\section{PENDAHULUAN}

Perilaku ibu hamil mempengaruhi kesehatan kehamilannya. Hasil studi pendahuluan di Kota Semarang menunjukkan bahwa BBLR masih sebagai penyebab kematian 
bayi tertinggi. ${ }^{1,2}$ Di Kota Semarang Angka Kematian Bayi pada tahun 2012 sebesar 293 kasus atau 10,7 per $1000 \mathrm{KH}$, pada tahun 2013 sebesar 251 kasus atau 9,5 per $1000 \mathrm{KH}$, pada tahun 2014 meningkat sebesar 253 kasus atau 9,8 per $1000 \mathrm{KH}$, pada tahun 2015 sebesar 229 kasus atau 8,38 per $1000 \mathrm{KH}$, tahun 2016 sebanyak 201 kasus kematian bayi atau 7,63 per $1000 \mathrm{KH}^{3,4}$

Berat bayi lahir rendah erat kaitannya dengan kesakitan dan kematian janin dan bayi, menghambat pertumbuhan, perkembangan kognitif, dan menyebabkan penyakit kronis di kemudian hari. Penurunan insiden BBLR membentuk kontribusi penting bagi pembangunan untuk mengurangi tingkat kematian anak. Oleh karena itu BBLR merupakan indikator penting untuk memantau kemajuan kesehatan suatu bangsa. ${ }^{5,6,7}$

Pendidikan kesehatan pada ibu hamil diharapkan terjadi pemberdayaan, sehingga ibu hamil dapat terbekali pengetahuan dan keterampilan yang terkait dengan kesehatannya sehingga ibu hamil sehat bayi lahir dengan sehat selamat. $^{8,9}$ Berkaitan dengan hal tersebut diperlukan media edukasi yang sesuai dengan sumberdaya yang tersedia baik sumber daya manusia maupun dana. ${ }^{10}$

Buklet kesehatan ibu hamil merupakan media pendidikan yang disusun berdasarkan prinsip bahwa pengetahuan yang ada diproyeksikan dalam bentuk gambar dan tulisan menarik yang diterima melalui indera penglihatan. Sehingga pesan-pesan kesehatan lebih mudah diterima oleh ibu hamil dan mendorong keinginan untuk lebih mendalami dan melaksanakan apa yang ada di dalamnya. ${ }^{10}$

Berdasarkan latar belakang tersebut, maka peneliti tertarik untuk melihat sejauh mana pengaruh pendidikan buklet kesehatan terhadap perilaku ibu hamil dalam upaya pencegahan Berat Bayi Lahir Rendah, dengan melihat perubahan pengetahuan, sikap dan praktik ibu hamil setelah diberikan pendidikan buklet kesehatan. Diharapkan hasil penelitian ini akan menjadi bahan pertimbangan dalam membantu mengatasi permasalahan kesehatan terkait upaya pencegahan BBLR di Kota Semarang.

\section{METODE PENELITIAN}

Riset ini dilakukan di Kota Semarang pada bulan Agustus-September 2017 dengan metode rancangan eksperimen semu dengan desain pre post test with control group. Populasi dalam penelitian ini adalah semua ibu hamil di Kota Semarang yaitu wilayah kerja Puskesmas Genuk dan wilayah kerja Puskesmas Tlogosari Wetan. Subjek peneltian sejumlah 82 ibu hamil yang dipilih secara simple purposive sampling. Data dikumpulkan dengan wawancara menggunakan kuesioner terstruktur. Data dianalisis dengan Mann whitney.

Variabel terikat yaitu perilaku ibu hamil meliputi pengetahuan, sikap dan praktik yang diukur dengan menggunakan kuesioner dan observasi perilaku. Variabel bebas adalah pendidikan kesehatan melalui buklet serta variabel pengganggunya meliputi sumber informasi lain dan pekerjaan ibu. Sumber informas lain adalah ibu yang tidak mendapatkan paparan informasi mengenai kesehatan kehamilan seperti seminar atau pelatihan. Pekerjaan ibu adalah ibu yang tidak bekerja dalam bidang kesehatan. 
Tabel 1. Deskripsi Dan Analisis Homogenitas Karakteristik Responden kelompok pelakuan dan kontrol

\begin{tabular}{|c|c|c|c|c|c|}
\hline Variabel & $\begin{array}{l}\text { Perlakuan } \\
\mathrm{n}(\%)\end{array}$ & $\begin{array}{l}\text { Kontrol } \\
\mathrm{n}(\%)\end{array}$ & $\begin{array}{c}\text { Perlakuan } \\
\text { Mean } \pm \text { SD }\end{array}$ & $\begin{array}{c}\text { Kontrol } \\
\text { Mean } \pm \text { SD }\end{array}$ & $p$-value $\left.{ }^{*}\right)$ \\
\hline \multicolumn{6}{|l|}{ Usia } \\
\hline$<21$ tahun & $3(7,3)$ & $3(7,3)$ & $27,4 \pm 5,7$ & $27,0 \pm 5,6$ & 0,820 \\
\hline 21-35tahun & $36(87,8)$ & $35(85,4)$ & & & \\
\hline$>35$ tahun & $2(4,9)$ & $3(7,3)$ & & & \\
\hline \multicolumn{6}{|l|}{ Gravida } \\
\hline Satu & $7(17,1)$ & $9(22)$ & & & \\
\hline Dua & $19(46,3)$ & $17(41,5)$ & $2,2 \pm 0,79$ & $2,2 \pm 2$ & 0,416 \\
\hline Tiga & $14(34,1)$ & $13(31,7)$ & & & \\
\hline Empat & $1(2,4)$ & $2(4,9)$ & & & \\
\hline \multicolumn{6}{|l|}{ Usia kehamilan } \\
\hline 13-28 minggu & $32(81)$ & $16(39)$ & $22,3 \pm 6,1$ & $23,5 \pm 6,6$ & 0,854 \\
\hline$<40$ minggu & $9(19)$ & $25(61)$ & & & \\
\hline \multicolumn{6}{|l|}{ Pendapatan ibu hamil } \\
\hline$<\mathrm{UMR}$ & $9(21,9)$ & $13(68,3)$ & $\begin{array}{c}2765853,6 \pm \\
655118,2\end{array}$ & $\begin{array}{l}2312195,1 \\
\pm 783005,4\end{array}$ & 0,069 \\
\hline$>$ UMR & $32(78,1)$ & $28(31,7)$ & & & \\
\hline \multicolumn{6}{|l|}{ Tingkat pendidikan } \\
\hline SD & $0(0)$ & $1(2,7)$ & & & \\
\hline SMP & $10(24,4)$ & $10(24,4)$ & & & 0,6 \\
\hline SMU & $23(56,1)$ & $25(61)$ & & & \\
\hline PT & $8(19,5)$ & $5(12,2)$ & & & \\
\hline
\end{tabular}

Hasil Deskripsi Pengetahuan, Sikap dan Praktek sebelum dan sesudah dilakukan intervensi dalam Upaya Pencegahan BBLR pada kelompok Perlakuan dan kelompok kontrol

Tabel 1. Deskripsi statistik Pengetahuan Ibu hamil Sebelum dan Sesudah pada Kelompok Perlakuan

\begin{tabular}{lcc}
\hline Pengetahuan & Pretest & Posttest \\
\hline Mean & 8,4 & 13,4 \\
Std. Deviation & 2,1 & 1,1 \\
Minimum & 5 & 11 \\
Maximum & 14 & 15 \\
\hline
\end{tabular}

Tabel 2. Deskripsi statistik Pengetahuan Ibu Hamil tentang Upaya Pencegahan BBLR Sebelum dan Sesudah pada Kelompok Kontrol

\begin{tabular}{lcc}
\hline Pengetahuan & Pretest & Posttest \\
\hline Mean & 7,3 & 11,1 \\
Std. & 2 & 1,3 \\
Deviation & & \\
Minimum & 3 & 9
\end{tabular}

\begin{tabular}{lll} 
Maximum & 11 & 13 \\
\hline
\end{tabular}

Tabel 3. Deskripsi Statistik Sikap Ibu Hamil tentang Upaya Pencegahan BBLR Sebelum dan Sesudah pada Kelompok Perlakuan

\begin{tabular}{lcc}
\hline Sikap & Pretest & Posttest \\
\hline Mean & 37,5 & 51,9 \\
Std. Deviation & 2,3 & 3,2 \\
Minimum & 28 & 43 \\
Maximum & 41 & 60 \\
\hline
\end{tabular}

Tabel 4. Deskripsi Statistik Sikap Ibu Hamil tentang Upaya Pencegahan BBLR Sebelum dan Sesudah pada Kelompok Kontrol

\begin{tabular}{lcc}
\hline Sikap & Pretest & Posttest \\
\hline Mean & 36,1 & 37,2 \\
Std. Deviation & 2,2 & 2,7 \\
Minimum & 28 & 28 \\
Maximum & 41 & 43 \\
\hline
\end{tabular}


Tabel 5. Deskripsi Statistik praktek Ibu Hamil tentang Upaya Pencegahan BBLR Sebelum dan Sesudah pada Kelompok Perlakuan

\begin{tabular}{lcc}
\hline Praktek & Pretest & Posttest \\
\hline Mean & 13,4 & 18,1 \\
Std. Deviation & 1,9 & 1,3 \\
Minimum & 8 & 13 \\
Maximum & 18 & 20 \\
\hline
\end{tabular}

Tabel 6. Deskripsi statistik praktek Ibu Hamil tentang Upaya Pencegahan BBLR Sebelum dan Sesudah pada Kelompok Kontrol

\begin{tabular}{lcc}
\hline Praktek & Pretest & Posttest \\
\hline Mean & 14 & 17,3 \\
Std. Deviation & 2,7 & 1,7 \\
Minimum & 7 & 12 \\
Maximum & 18 & 19 \\
\hline
\end{tabular}

\section{HASIL DAN PEMBAHASAN}

\section{Hasil Penelitian}

Tabel 1 menunjukkan umur responden pada kelompok perlakuan berumur 27 tahun dengan umur terendah 19 tahun dan umur tertinggi 40 tahun, sedangkan pada kelompok kontrol rata-rata responden berumur 27 tahun dengan umur terendah 20 tahun dan umur tertinggi 42 tahun. Rata-rata gravida pada kelompok perlakuan dan kontrol adalah gravida ke 2, gravida terendah dan terbanyak 4. rata-rata umur kehamilan responden pada kelompok perlakuan adalah kehamilan berumur 22 minggu, dengan umur kehamilan terendah 13 minggu dan tertinggi 34 minggu. Pendapatan rata-rata responden pada kelompok perlakuan adalah Rp2.765.853.6,- dengan pendapatan terendah sebesar Rp.1.700.000,- dan pendapatan tertinggi sebesar Rp4.500.000,-. Sedangkan pendapatan rata-rata responden pada kelompok kontrol adalah Rp2.312.195.1,- dengan pendapatan terendah sebesar Rp1.200.000,- dan pendapatan tertinggi sebesar Rp4500.000. Sebagian besar ibu hamil berpendidikan SMU yaitu berjumlah $48 \mathrm{ibu}$ hamil, terdiri dari $23 \mathrm{ibu}$ hamil $(56,1 \%)$ pada kelompok perlakuan dan 25 ibu hamil $(61,0 \%)$ pada kelompok kontrol. Pendidikan terendah responden adalah SD berjumlah 1 orang $(2,4 \%)$ pada kelompok perlakuan, sedangkan pendidikan tertinggi adalah perguruan tinggi berjumlah $12 \mathrm{ibu}$ hamil, terdiri dari $7(17,1 \%)$ ibu hamil pada kelompok perlakuan dan 5 (12,2\%) ibu hamil pada kelompok kontrol.

Hasil penelitian tabel 2 sampai tabel 6 menunjukan adanya peningkatan rerata skor pengetahuan pada kelompok intervensi dari $8,4 \pm 2,1$ (5-14) menjadi 13,4 $\pm 1,1$ (11-15) dengan nilai $\mathrm{p}=0,001$, sedangkan pada kelompok kontrol dari 7,3 \pm 2,0 (3-11) menjadi $11,1 \pm 1,3$ (9-13) dengan nilai $\mathrm{p}=0,001$. Peningkatan rerata skor sikap dari $37,5 \pm 2,3$ (28-41) menjadi 51,9 \pm 3,2 (43-60) dengan nilai $\mathrm{p}=0,001$, sedangkan pada kelompok kontrol dari $36,1 \pm 2,2$ (28-41) menjadi $37,2 \pm 2,7$ (28-43) dengan nilai $\mathrm{p}=0,001$. Peningkatan rerata skor praktik dari $13,4 \pm 1,9$ (8-18) menjadi $18,1 \pm 1,3$ (13-20) dengan nilai $\mathrm{p}=0,001$ sedangkan kelompok kontrol dari $14 \pm 2,7$ (7-18) menjadi 17,3 $\pm 1,7$ (12-19) dengan nilai $p=0,018$. Peningkatan skor pengetahuan $(\mathrm{p}<0,05)$, peningkatan sikap $(\mathrm{p}<0,05)$ dan praktik $(p<0,05)$ pada kelompok intervensi lebih tinggi dibanding kelompok kontrol.

\section{Pembahasan}

Analisis Perbedaan perubahan

Pengetahuan Ibu Hamil Terkait Upaya Pencegahan BBLR antara kelompok perlakuan dan kelompok kontrol.

Hasil penelitian menunjukkan bahwa ada perbedaan perubahan pengetahuan Ibu hamil yang signifikan terkait upaya pencegahan BBLR antara kelompok intervensi dan kelompok kontrol $(p=0,006)$. Nilai rerata selisih tingkat pengetahuan pada kelompok intervensi $(5,0)$ lebih tinggi dibandingkan pada kelompok kontrol $(3,8)$. 
Hal ini menunjukkan bahwa pemberian pendidikan kesehatan dengan menggunakan media buklet lebih efektif dalam meningkatkan pengetahuan ibu hamil tentang kesehatan kehamilan terkait upaya pencegahan BBLR dibandingkan dengan yang tidak diberikan perlakuan.

Pengetahuan ibu hamil pada kelompok perlakuan dan kontrol meningkat secara bermakna, hal ini sesuai teori Lawrence Green bahwa faktor pemungkin (enabling factor) yang terwujud dalam ketersediaan sumberdaya pendidikan buklet kesehatan terkait upaya pencegahan BBLR dapat memberikan akibat pada faktor predisposisi (predisposisi factor) berupa perubahan pengetahuan. Perubahan pengetahuan yang meningkat akan sejalan dengan sikap yang ditimbulkan ibu hamil dalam kesehatan kehamilannya ${ }^{11,12}$.

Analisis Perbedaan perubahan Sikap Ibu Hamil Terkait Upaya Pencegahan BBLR Antara Kelompok Perlakuan Dan Kelompok Kontrol

Hasil penelitian menunjukkan ada perbedaan perubahan sikap Ibu hamil yang signifikan terkait upaya pencegahan BBLR antara kelompok intervensi dan kelompok kontrol $(p=0,000)$. Nilai rerata selisih sikap pada kelompok intervensi $(14,3)$ lebih tinggi dibandingkan pada kelompok kontrol $(1,0)$. Hal ini menunjukkan bahwa pemberian pendidikan kesehatan dengan menggunakan media buklet lebih efektif dalam meningkatkan sikap ibu hamil tentang kesehatan kehamilan terkait upaya pencegahan BBLR dibandingkan dengan yang tidak diberikan perlakuan.

Perubahan sikap pada kedua kelompok dipengaruhi oleh media yang digunakan pada saat penelitian berlangsung. Hal ini sesuai dengan teori yang dikemukakan Notoatmodjo bahwa perubahan sikap merupakan hasil belajar dimana proses belajar terjadi pengaruh timbal balik antara berbagai faktor; subjek belajar, pengajar atau fasilitator belajar, metode yang digunakan, materi atau bahan yang dipelajari dan alat bantu belajar (media). Peningkatan sikap yang terjadi pada responden dapat disebabkan oleh pengetahuan yang diperoleh sehingga memunculkan pemahaman dan keyakinan terhadap kebutuhan mereka yang memang harus melakukan deteksi dini dan tatalaksana penyimpangan pertumbuhan melalui materi yang diberikan yaitu media buklet. Tingkat pengetahuan seseorang dapat mempengaruhi sikap orang tersebut terhadap suatu objek. Seseorang yang memiliki pengetahuan yang baik terhadap suatu objek akan memberikan respon yang lebih rasional dan akan berpikir sejauh mana keuntungan atau kerugian yang mungkin akan diperoleh dari objek tersebut ${ }^{41}$. Hal ini sejalan dengan penelitian Pratiwi yang menyatakan bahwa sikap ibu positif terhadap upaya pencegahan gizi buruk balita setelah mendapatkan pendidikan kesehatan berupa konseling gizi $^{13,14,15}$

Analisis Perbedaan perubahan Praktik Ibu Hamil Terkait Upaya Pencegahan BBLR antara kelompok perlakuan dan kelompok kontrol.

Hasil penelitian menunjukkan bahwa ada perbedaan perubahan Praktek Ibu hamil yang signifikan terkait upaya pencegahan BBLR antara kelompok intervensi dan kelompok kontrol $(\mathrm{p}=0,000)$. Nilai rerata selisih praktek pada kelompok intervensi $(4,7)$ lebih tinggi dibandingkan pada kelompok kontrol (3,3). Pemberian pendidikan kesehatan dengan menggunakan media buklet lebih efektif dalam meningkatkan praktek ibu hamil tentang kesehatan kehamilan terkait upaya pencegahan BBLR dibandingkan dengan yang tidak diberikan perlakuan. 
Praktik ibu hamil pada kelompok perlakuan mengalami peningkatan setelah diberikan pendidikan. Sejalan dengan teori Brigham dalam Rahmawati bahwa hubungan praktik atau tindakan sangat dipengaruhi oleh fungsi karakteristik individu dan faktor lingkungan. Karakteristik individu saling berinteraksi satu sama lain dan kemudian berinteraksi pula dengan faktor lingkungan sehingga menentukan praktik atau tindakan ${ }^{17,18,19}$. Karakteristik individu dalam responden meliputi umur dan gravida, hal ini selanjutnya saling berinteraksi dengan faktor lingkungan yaitu edukasi deteksi dini dan tatalaksana penyimpangan perubahan yang didapat selama $14-21$ hari sehingga responden dapat meningkatkan praktik dalam upaya pencegahan BBLR ${ }^{20,21}$.

\section{KESIMPULAN}

Hasil analisis menunjukkan Buklet kesehatan berpengaruh terhadap perilaku Ibu hamil. Maka penting bagi stakeholder untuk melakukan pengawasan dan pemantauan setiap pelaksanaan kegiatan yang dilakukan dalam mendukung kesehatan ibu hamil terkait upaya pencegahan BBLR.

Hasil penelitian dapat dijadikan sebagai referensi penelitian selanjutnya terkait kesehatan reproduksi serta penggunaan media dan metode lain seperti video. Selain itu, peneliti selanjutnya dapat melakukan penelitian dengan mengikuti hasil intervensi terhadap responden sampai bayi lahir untuk melihat perubahan yang terjadi.

\section{UCAPAN TERIMA KASIH}

Peneliti mengucapkan terimakasih yang sebesar-besarnya kepada puskesmas Tlogosari Wetan dan Puskesmas Genuk yang telah memberikan ijin serta menfasilitasi dalam pelaksaaan penelitian ini.

\section{DAFTAR PUSTAKA}

1. Hoelman, M, B. Tua, P,P. Sutoro. Panduan SDGs Untuk Pemerintah Daerah (Kota Dan Kabupaten) Dan Pemangku Kepentingan Daerah, Jakarta: INFID; 2015

2. WHO. The United Nations Children's Fund And World Health Organization. Low Birth Weight Country, Regional And Global Estimates. New York: WHO; 2004

3. Muthayya, S. Maternal Nutrition And Low Birth Weight - What Is Really Important?. J Med Res Indian in NCBI PubLMed.2009 nov; vol 130; No 5; 600-8

4. Kementrian Kesehatan RI. Riset Kesehatan Dasar (RISKESDAS) 2013 Badan Penelitian Pengembangan Kementrian Kesehatan RI. Jakarta: Kemenkes RI; 2014

5. Dinkes Propinsi Jawa Tengah. Buku Saku Kesehatan Tahun 2015. Semarang: Dinas Kesehatan Jawa Tengah; 2016

6. Dinas KesehaTan Kota Semarang. Profil Kesehatan Kota Semarang Tahun 2015. Semarang: Dinkes Kota Semarang; 2015

7. Dinas Kesehatan Kota Semarang. Profil Kesehatan Kota Semarang Tahun 2016. Semarang: Dinkes Kota Semarang; 2016

8. SDKI. Badan Kependudukan Dan Keluarga Berencana Nasional tahun 2012 Survey Demografi Dan Kesehatan Indonesia. Jakarta: Badan Koordinasi Keluarga Berencana Nasional; 2013

9. Kementrian Kesehatan RI. Profil Kesehatan Indonesia Tahun 2015. Jakarta: Kemenkes RI; 2016

10. Dinas Kesehatan Propinsi Jawa Tengah. Profil Kesehatan Jawa 
Tengah Tahun 2015. Semarang:

Dinkes Semarang; 2016

11. Verhoefffh, L, S. Kalande, B, F. Kazembepn. Broadhead, R, L. Et A1. Post Neonatal Infant Mortality In Malawi: The Importance Of Maternal Health. J Ann Trop Paediatric. 2014; 24:169-161

12. Halder, K, R. Haque, I. Faisal, M. Hasan, M. Chowdhury, M. Status

Of Knowledge On The Risk Factors Of Low Birth Weight Among The Women Of Reproductive Age In Rural Bangladesh. J Epidemiology OMICS International.

Bangladesh:

Department Of Public Health Daffodil International University Of Dhaka; 2017

13. Stalker, P. Millenium Development Goals. Jakarta: BAPPENAS dan UNDP; 2008

14. Departemen Kesehatan RI. Sistem Kesehatan Nasional. Jakarta: Departemen Kesehatan RI; 2009

15. Setiawati, D. Pendidikan Kesehatan. Jakarta: Trans Info Media; 2010

16. Notoadmojo, S. Promosi Kesehatan Dan Ilmu Perilaku. Jakarta: Rieneka Cipta; 2007

17. Nabiwemba, E, L. Atuyambe, L. Criel, B. Kolsteren, P. Orach, C, G. Recognition And Home Care Of Low Birth Weight Neonates: A Qualitative Study Of Knowledge, Beliefs And Practices Of Mothers In IgangaMayuge Health And Demographic Surveillance Site. Uganda. J BMC Public Health in NCBI PubLMed. Juni 2014; 14: 546

18. Darmstadt, G, L. Kumar, V. Yadav, R. Shearer, J. C. Baqui, A. H. Awasthi, S. Singh, J,V. Mehrotra, H.
Srivastava, K. Gupta, A. Sharma, A. Winch, P, J. Santosham, M. The Saksham Study Group. Community Perceptions Of Birth Weight In Rural Uttar Pradesh, India: Implications For Care Of Low-Birth-Weight Infants. J Perinatol. 2008; 28(Suppl 2):S53-S60.

19. Tayebeh, K, I. Heshmati, H. Faryabi, R. Goudarzian, Z. Ghodrati, A. Najafi, F. Alizadeh, H. Effect of Health Belief Model based education on nutritional behaviors of pregnant women referred to health centers in Torbat-e-heydariych city Iran. J of health in Elsevier.2016;vol;no.3

20. Ford, K. Weglicki, L. Kershaw, T. Schram, C. Hoyer, P, J. Mary, L, J. Effects of a prenatal care intervention for adolescent mothers on birth weight, repeat pregnancy, and educational outcomes at one years post partum, in Detroit, Michigan. J Perinat educ. 2002; vol 11 ; no $1 ; 35-38$

21. Ekhtiari, Y, S. Majlessi, F. Foroushani, A, R. Shakibazadeh, E. Effect of a Self-care Educational Program Based on the Health Belief Model on Reducing Low Birth Weight Among Pregnant Iranian Women, Iran. Int J Prev Med PMC. 2014; vol 5; no 1 ; 76-82. 